BBA 453 I 5

\title{
ON THE NATURE OF THE "NON-SATURABLE" MIGRATION OF AMINO ACIDS INTO EHRLICH CELLS AND INTO RAT JEJUNUM
}

HALVOR N. CHRISTENSEN AND MARIE LIANG

Depariment of Biological Chemistry, The University of Michigan, Ann Arbor, Mich. (U.S.A.)

(Received July Igth, I965)

\section{SUMMARY}

The so-called non-saturable uptake of $\alpha$-amino acids by the Ehrlich cell, even though it occurs at a characteristically slow rate for various neutral amino acids (whether they are in the D- or the L-form) is nevertheless structurally specific, since the uptake of $\beta$-alanine, taurine and betaine occurs only about one-third as rapidly as that of the $\alpha$-amino acids. Furthermore the uptake shows a considerable sensitivity to $\mathrm{pH}$, and a temperature sensitivity so high as to exclude simple diffusion as the rate-limiting step. The structural specificity is compatible with a reaction of the amino acid with a membrane site, either an abundant one or a relatively unreactive one, the reaction of the amino acid with which presumably need involve at most only its amino and carboxyl groups.

Uptake of amino acids at high levels by rat-intestinal segments also showed high temperature sensitivities.

\section{INTRODUCTION}

The several tissues and cells that have been studied show, in addition to the usual amino acid transport systems, a comparatively slow uptake and release of neutral amino acids, natural or unnatural, metabolizable and non-metabolizable, which fails to be saturated by any reasonable concentration of the amino acid or an analog. Instead, its rate increases linearly with concentration, at least up to o.I M levels. Akedo And Christensen ${ }^{1}$ showed that this component can readily be measured by extending observations of the uptake rate to high levels and then extrapolating to infinite concentrations. If this correction is not made, the customary kinetic plots may curve in characteristic ways at high solute concentrations; the Lineweaver-Burk plot, for example, curves downward toward the origin. The magnitude of the error produced in estimating $K_{m}$ and $V$ depends on the quantitative relation between $V / K_{m}$ (the value to which $V /\left(K_{m}+[S]\right)$ reduces for low solute concentrations, and hence the rate constant for the saturable process at such concentrations) and the linear constant describing the "non-saturable" process.

We have emphasized from the first that the "non-saturable" component may well be simply another mediated transport which we have not yet been able to saturate measurably, nor to slow appreciably by a suitable competing analog. A number of investigators have assumed the "non-saturable" uptake to occur by dif- 
fusion. If it were practical to test solute levels at still higher levels, saturability might well become evident; but of course a slowing of the relative uptake rate at very high levels might result from the replacement of the environmental $\mathrm{Na}^{+}$or $\mathrm{Cl}^{-}$by the amino acid, from effects on water distribution, or from handicaps to energy metabolism or other general functions of the cell. Therefore one does not prove that the process in question is simple diffusion merely by showing that it cannot be saturated. The present communication describes some other tests of the nature of the "non-saturable" migration into the Ehrlich cell, and into intestinal segments, leading us to the conclusion that it very likely is an additional chemically mediated transport.

\section{METHODS}

The Ehrlich ascites tumor cells were produced and handled by the methods previously described ${ }^{3-6}$. The suspending medium was Krebs-Ringer bicarbonate medium, in which amino acids replaced $\mathrm{NaCl}$ isoosmotically. For studying the effect of modifying the $\mathrm{pH}$, Krebs-Ringer phosphate medium was prepared to yield the desired $\mathrm{pH}$ at essentially the same osmotic pressure.

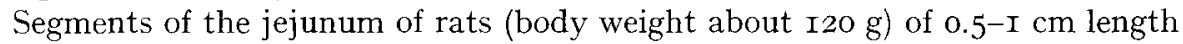
were incubated in Krebs-Ringer bicarbonate medium containing $0.5 \%$ glucose, prepared as described above, for $5 \mathrm{~min}$ for observation of $\alpha$-aminoisobutyric acid and phenylalanine uptake, respectively. This interval was short enough to approximate the initial rates of uptake. The tissue was removed from the suspending medium with forceps and blotted gently. It was then homogenized with a mixture of $2 \%$ $\mathrm{ZnSO}_{4}$ and o.I $\mathrm{M} \mathrm{NaOH}$, each $5 \mathrm{ml} / \mathrm{g}$ of tissue. The extract and the suspending phase were then analyzed by liquid scintillation counting, correction being made for the extracellular space of the tissue, observed using poly $\left[{ }^{14} \mathrm{C}\right]$ glucose.

\section{RESULTS}

\section{Effect of relative magnitude of non-saturable component on its discrimination}

Fig. IA shows the calculated sum of the migration of a solute by a saturable and a non-saturable route, assuming three different orders of magnitude for $K_{m}$, a fixed value for the $V$ of the saturable route, and a fixed value for the rate constant describing the non-saturable process,

$$
v=K_{\mathrm{D}}\left(A_{\mathrm{c}}-A_{\mathrm{f}}\right)
$$

where $A_{\mathrm{c}}$ and $A_{\mathrm{f}}$ are the calculated internal and external concentrations of solute ${ }^{1}$. The upper curve resembles the findings on the predominant mode of phenylalanine uptake by the Ehrlich cell. For this curve $V / K_{m}$ has been set equal to Ioo $K_{\mathbf{D}}$, so that the non-saturable component approaches a minimal value of $I \%$ of the total uptake at low solute concentrations. Under these conditions, good approximations of $K_{m}$ and $V$ can be obtained without correcting at all for the non-saturable process; if observations were limited to levels below ro $\mathrm{mM}$ the slower linear component would probably not be detected. The middle curve resembles findings for the uptake of glycine by the same cell. In this case $V / K_{m}$ equals Io $K_{\mathrm{D}}$, so that the non-saturable component represents Io \% or more of the total uptake. Failure to take the "nonsaturable" component into account would in this case lead to considerable error. 
For a similar case, Fig. 2 of a recent communication ${ }^{2}$ illustrates the effects on the Lineweaver-Burk plot of not segregating the saturable component from the "nonsaturable". Fig. IB (the two upper curves) shows that the plot proposed by AkEDo AND CHRISTENSEN measures well the "non-saturable" component under either of the first two conditions.
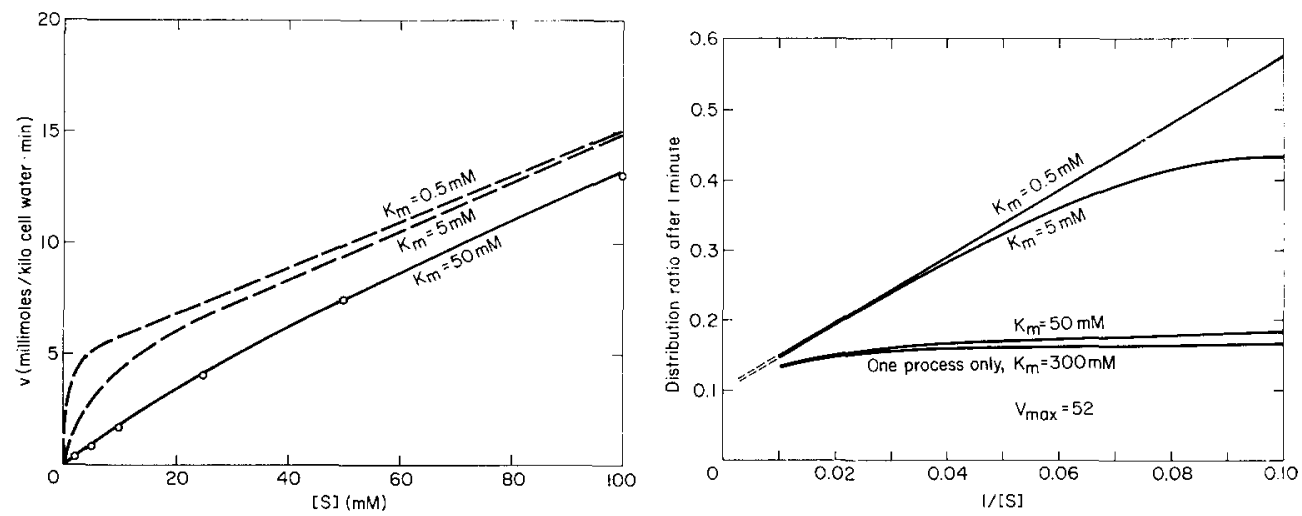

Fig. I. Total uptake by the sum of two processes, one "non-saturable" and the other saturable, with $K_{m}$ values of $0.5,5$ and $5^{\circ} \mathrm{mM}$. $V$ has been held constant at 5 mmoles per $\mathrm{kg}$ cell water per min. The first-order rate constant, $K_{\mathrm{D}}$, describing the "non-saturable" process ${ }^{1}$ has been held at $0 . \mathrm{min}^{-1}$. The circles along the lower curve represent uptake by a single agency, $K_{m}=$ $300 \mathrm{mM}$. In Fig. IB, the same data are plotted according to AkEdo And Christensen ${ }^{1}$. The lincar rate constant is obtained from the intercept at $I /\left[S_{]}=\right.$zero; the intercept is cqual to $\mathrm{I}-\mathrm{e}^{-K} \mathrm{D}^{t}$. See text for interpretation.

For the lowest curve of Fig. IA, $V / K_{m}=K_{\mathrm{D}}$, so that the "non-saturable" process accounts for half or more of the total uptake. The saturable process in this case contributes too little curvature to the plot to permit the nature of the curve to be recognized. The six points plotted along this lowest curve are calculated to represent uptake by a single process with a $K_{m}$ of $0.3 \mathrm{M}$. Their position shows that it would be difficult to decide whether or not the curvature of the lowest line arose from a combination of a saturable with a non-saturable process, or simply from a high- $K_{m}$, saturable process.

Replotting the data of the lowest curve of Fig. IA according to the method of AkEdo (Fig. IB, next to lowest curve), and extrapolation of the linear portion of the resultant curve to infinite concentration, leads to an apparently acceptable value for the rate constant of the non-saturable process. The procedure may be seen to be unreliable under these conditions, however, because essentially the same extrapolated value is suggested by the lowest curve of Fig. IB, which in fact has been constructed to describe uptake exclusively by a saturable process.

Accordingly, the method for correcting the total uptake rate for the suspected presence of a non-saturable process, by proceeding to high enough solute levels to secure a linear section in the plot proposed by AKEDO AND CHRISTExser, tends to fail when the value of $V / K_{m}$ of a mediated process comes to have the same order of magnitude as $K_{\mathrm{D}}$ for the supposedly non-saturable component.

\section{Properties of the non-saturable component}

Table I shows the rates of uptake by the Ehrlich cell observed for several sub- 
stances as measured at concentrations of roo $\mathrm{mM}$ or higher. In the case of $\mathrm{D}$-alanine, Ioo $\mathrm{mM} \mathrm{L}$-alanine was used to saturate the known systems accessible to $\mathrm{D}$-alanine.

TABLE I

RATES OF "NON-SATURABLE" UPTAKE OF SOME AMINO ACIDS BY THE EHRLICH CELL DETERMINED BY THE METHOD OF AKEDO AND ChRISTENSEN ${ }^{1}$ FOR THE INTERVAL I TO IO min AFTER ADDING THE RADIOACTIVE SUBSTANCE

Temperature $37^{\circ}$. To ensure nearly complete saturation of the high- $K_{m}$ transports of $D$-alanine and betaine, Ioo $\mathbf{m M} \mathbf{L}$-alanine was included in the medium.

\begin{tabular}{ll}
\hline Substance & $\begin{array}{l}K_{D} \text { for non- } \\
\text { saturable uptake } \\
\left(\text { min }^{-1}\right)\end{array}$ \\
\hline L-Alanine & 0.03 \\
D-Alanine & 0.03 \\
$\beta$-Alanine & 0.01 \\
Taurine & 0.007 \\
Betaine & 0.01 \\
\hline
\end{tabular}

Nearly all of the transport of D-alanine has been shown to be carried out by the "uphill" system serving for L-alanine, glycine, L-serine and numerous other neutral amino acids, a system described elsewhere in detail under the designation $A$ (for alanine-preferring) ${ }^{6}$. The observations of Table I are for the 9 -min interval, I to Io min. During the first minute the "non-saturable" uptake typically has a mean rate three times as great as it shows subsequently. Although the excess of uptake during the first minute appears to have somewhat the same properties as the subsequent slower uptake, it has been omitted from consideration in the present study. This excess of uptake during the first minute could not be significantly modified by collecting cells as early as possible during the development of the Ehrlich tumor, or by taking cells from near the surface or deeper in the pellet after slowly centrifuging ascitic fluid or resuspensions of the ascites cells.

The results of Table I show that D-alanine enters the cell by the "non-saturable" route as rapidly as does $\mathrm{L}$-alanine. The same rates were obtained for $\mathrm{D}$ - and $\mathrm{L}$-valine and for other neutral amino acids. We have already reported this correspondence for shorter time intervals both for alanine and valine ${ }^{5}$. If the Ehrlich cell had a special transport system for D-amino acids, or for D-alanine specifically, one not accessible to the $\mathrm{L}$-isomers, its uptake should retain a degree of concentration dependence in the presence of Ioo $\mathrm{mM} \mathrm{L}$-alanine. Fig. 2 shows very nearly the same rates of uptake after the first minute for I and $20 \mathrm{mM}$ D-alanine. On the other hand, the uptake of taurine or betaine retains a distinct degree of concentration dependence in the presence of Ioo $\mathrm{mM}$ L-alanine. Measurements by the same procedure indicated by Fig. 2 show the presence of a very slow, saturable system for taurine, $K_{m}=0.6 \mathrm{mM}, V=0.085$ mmole per $\mathrm{kg}$ cell water per min, whose correspondence to the Michaelis-Menten equation is illustrated by the plot by the method of Augustinsson in Fig. 3. One cannot assume that the kinetic parameters obtained have been entirely uninfluenced by the presence of the alanine at Ioo mM. Nevertheless, taurine and betaine must each have a slow uptake by a mediated route, in addition to the ordinary "alaninepreferring" system by which most of the uptake of betaine occurs? , and, in the case 
of taurine, in addition to the system by which most of the uptake of taurine and $\beta$-alanine occurs ${ }^{8}$. Both of the latter systems are almost entirely blocked by roo $\mathrm{mM}$ L-alanine.

Table I shows that the non-saturable process is structurally specific, admitting betaine (cf. ref. 7 ), $\beta$-alanine ( $c f$. ref. 8 ) and taurine much more slowly than it does the neutral D- and L-amino acids. L-Aspartic acid, even at low concentrations, is also taken up very slowly by the Ehrlich cell ${ }^{2}$.

Fig. 2 shows that the migration of $\mathrm{D}$-alanine in the presence of $100 \mathrm{mM} \mathrm{L}$-alanine has a high temperature sensitivity, with a mean $Q_{10}{ }^{\circ}$ of 3.0. The more slowly migrating taurine shows a lower $Q_{10^{\circ}}$ of $I_{15}$ at high concentrations or in the presence of high levels of $\beta$-alanine; conceivably a large part of its migration actually occurs by simple
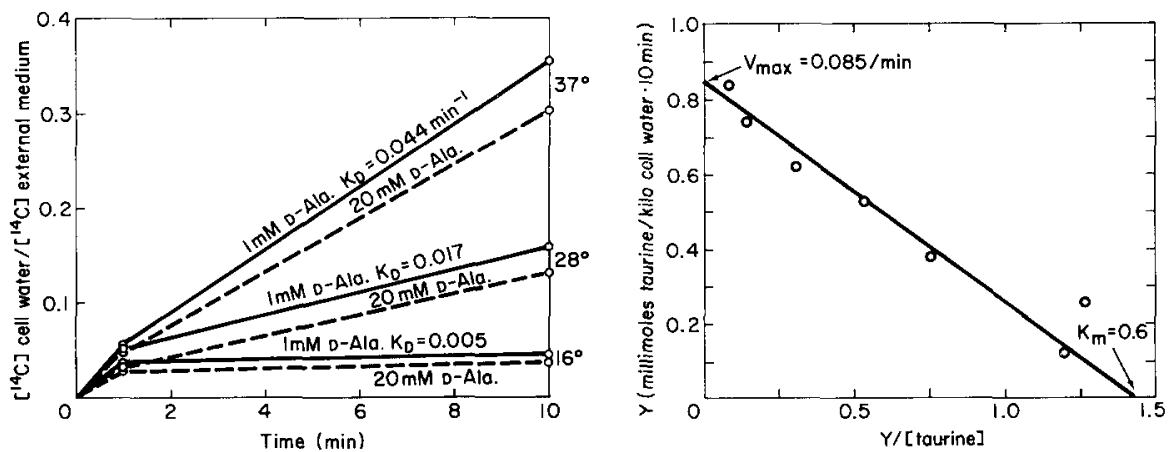

Fig. 2. Temperature sensitivity and concentration dependence for the uptake of $D$-alanine by the Ehrlich cell in the presence of $100 \mathrm{mM} \mathrm{L-alanine.} \mathrm{The} Q_{10}=$ for both temperature intervals is 3 for the time interval $\mathrm{I}$ to $\mathrm{I}$ o min. Near parallelism for the lines for $\mathrm{I}$ and $20 \mathrm{mM} \mathrm{D}$-alanine shows that concentration dependence is insignificant in the interval, I to Io min. The slopes of the solid lines correspond to $K_{\mathrm{D}}=0.044 \mathrm{~min}^{-1}$ (uppermost); $K_{\mathrm{D}}=0.017 \mathrm{~min}^{-1}$ (second line); $K_{\mathrm{D}}=0.005$ (bottom line).

Fig. 3. Kinetic parameters for a slow uptake for taurine observed in the presence of Ioo $\mathrm{mM}$ L-alanine. Temperature $37^{\circ}$; $\mathrm{pH} 7.4$; time interval for uptake Io min. The uptake rate has been corrected for the non-saturable component ${ }^{1}$.
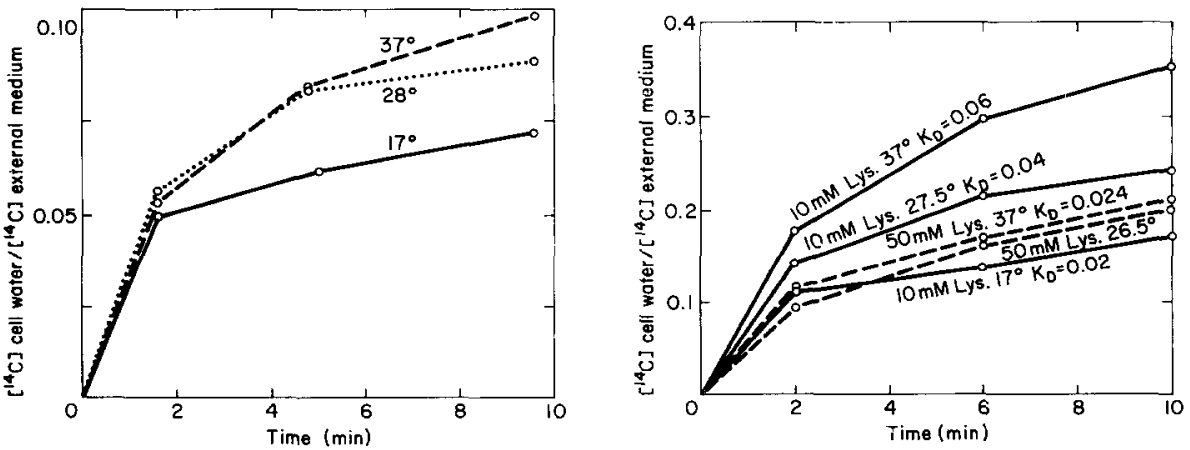

Fig. 4. Temperature sensitivity of the uptake of I $\mathrm{mM}\left[{ }^{\mathbf{1 4}} \mathrm{C}\right]$ taurine in the presence of $100 \mathrm{mM}$ $\beta$-alanine. The mean $Q_{10}$ for the time interval I to 10 min was I.6.

Fig. 5. Sensitivity to temperature of the uptake of L-lysine at 10 and $50 \mathrm{mM}$, in the presence of $50 \mathrm{mM}$ L-phenylalanine. The dotted lines are for $50 \mathrm{mM}$ lysine at $37^{\circ}$ and $26.5^{\circ}$. At this concentration the $Q_{10^{\circ}}$ is very close to unity, whereas at ro $\mathrm{mM}$ it is about 1.5 . 
diffusion (Fig. 4). For L-lysine, the $Q_{10}{ }^{\circ}$ values for uptake decreased from I.5 to I.I as the concentration was raised from ro to $50 \mathrm{mM}$, in the presence of $50 \mathrm{mM}$ L-phenylalanine (Fig. 5). Even at the higher lysine level one of the mediated systems for lysine uptake appears to be by no means saturated ${ }^{9}$.

The temperature sensitivity of amino acid uptake by jejunal segments ${ }^{10}$ from the rat was also studied, using 75 and $150 \mathrm{mM}$ levels to saturate ordinary transport systems. For L-phenylalanine $Q_{10}{ }^{\circ}$ values of 2.5 and 4.8 were obtained in two different experiments of 5 min duration, for the range $37^{\circ}$ to $27^{\circ}$; for $\alpha$-aminoisobutyric acid a typical value of 2.4 was observed.

TABLE II

pH SENSitivity oF THE NON-Saturable UPTAKE OF D-ALANine

In Krebs-Ringer phosphate medium, containing Ioo $\mathrm{mM}$ L-alanine and $20 \mathrm{mM} \mathrm{D}-\left[{ }^{14} \mathrm{C}\right]$ alanine, replacing $\mathrm{NaCl}$, 60 mmoles/l. Temperature, $37^{\circ}$; time intervals after adding the labeled substance, as shown.

\begin{tabular}{lll}
\hline pH & \multicolumn{2}{l}{$K_{D}\left(\mathrm{~min}^{-1}\right)$} \\
\cline { 2 - 3 } & $\begin{array}{l}\text { Expt. I } \\
2-I O \text { min }\end{array}$ & $\begin{array}{l}\text { Expt. } 2 \\
6-I O \text { min }\end{array}$ \\
\hline 7.4 & 0.028 & 0.025 \\
7.0 & 0.018 & 0.018 \\
6.5 & 0.015 & 0.004 \\
6.0 & 0.007 & 0.002 \\
\hline
\end{tabular}

Table II shows that the non-saturable migration is sharply decreased by lowering the $\mathrm{pH}$ to 6 , the decrease being of about the same degree as that for uptake by the $A$ transport system ${ }^{6}$. The agency by which most of the migration of such amino acids as phenylalanine and leucine occurs is scarcely affected by that change in $\mathrm{pH}$. The uptake of D-alanine in the presence of Ioo $\mathrm{mM} \mathrm{L}$-alanine resembles, however, the uptake of the leucine group rather than of the alanine group in being little affected by substituting choline for all the $\mathrm{Na}^{+}$, or all but 25 mequiv/l of the $\mathrm{Na}^{+}$, in KrebsRinger bicarbonate medium, the $K_{\mathrm{D}}$ remaining within $6 \%$ of $0.03 \mathrm{~min}^{-1}$ (interval $\mathrm{I}$ to ro min after adding $\mathrm{D}$-alanine).

\section{DISCUSSION}

The "non-saturable" migration of amino acids has three features that show it does not occur by simple diffusion, but instead probably also requires at least a momentary association of chemical groups of the amino acid with chemical groups in the barrier membrane.

(I) It shows chemical specificity. Differences in molecular size do not appear likely to permit $\alpha$-alanine to pass the membrane more rapidly than $\beta$-alanine by simple diffusion. In the case of betaine, one could conceive that the absence of a dissociable proton on the $\mathrm{N}$ atom might prevent the formation even to the extent of a few parts per million of a totally uncharged species, which could conceivably be the form of ordinary $\alpha$-amino acids passing through the lipid barrier of the plasma membrane. This explanation is rendered improbable, however, by the inability of $\beta$-alanine to 
migrate at more than about one-third the rate of $\alpha$-alanine. If one tabulates the $\mathrm{p} K^{\prime}$ values for various $\alpha$-amino acids and for $\beta$-alanine, one finds no encouragement for the view that a greater abundance of the uncharged species of the former accounts for their faster passage across the membrane at high concentrations.

(2) Ordinary neutral amino acids showing typical rates for the non-saturable migration have $Q_{10}{ }^{\circ}$ values of about 3 , a value that may be taken to exclude simple diffusion as the rate-limiting step. The lower value observed for the more slowly migrating taurine may mean that a larger portion of its uptake occurs by simple diffusion. Only in the case of lysine were $Q_{10}{ }^{\circ}$ values close to unity observed. Even when such low $Q_{10}{ }^{\circ}$ values are observed one still cannot suppose that simple diffusion has been established as the mode of uptake. Attempts to complete the saturation of lysine uptake, and thereby to establish the steady-state position of lysine transport at saturating levels of inhibitory amino acids, have not given convincing results, presumably because the conditions used do not saturate a second, low-affinity mediating system which we have described under the designation $A^{+}$(ref. 9). One should note that the correction of AKEDO AND CHRISTENSEN ${ }^{\mathbf{1}}$ cannot be generally applied without making an assumption as to the position of the steady state of the nonsaturable process. For a cationic amino acid the steady state in the absence of uphill transport might be expected to lie at a distribution ratio of $1.5-2.5$, if we take the interior of the cell to be $12-24 \mathrm{mV}$ negative with respect to the external environment ${ }^{11}$.

(3) The non-saturable migration is sharply decreased by lowering the $\mathrm{pH}$ successively from 7.4 to 7.0 , to 6.5 and to 6.0 . Changes of $\mathrm{pH}$ in this range might not be expected to change significantly the state of charge of the neutral amino acids, although they probably would change the state of dissociation of accessible groups in the plasma membrane, and perhaps also some metabolic processes within the cell.

We may consider what sort of a reactive site might serve to bind or orientate the $\alpha$-amino acid molecule in a way favorable to its passage through the plasma membrane, and yet show the low structural specificity described. From the indifference of the non-saturable transport to the nature of the side chain of the $\alpha$-amino acid, whether it be a benzyl group, a methyl group, or entirely absent, and to the position of the side chain, whether that typical of the $\mathrm{L}^{-}$or of the D-amino acids, we may suppose that not more than two chemical groups on the amino acid molecule are bound, and that the side chain does not figure in the binding, as it appears to do for the known saturable transport systems for amino acids. The structural specificity observed for the non-saturable route concerns instead the distance between the amino and the carboxyl groups, and the nature of the amino group, whether it be quaternary or not. Furthermore the lowering of the $\mathrm{pH}$ might very plausibly influence the behavior of a membrane group of a type that could link to the amino or carboxyl group, and less likely that of a group able to form an apolar bond with the amino acid side chain. Thus we visualize a reactive site composed of at most two elements, one able to bond to the amino group, the other to the carboxyl group. To account for the difficulty of saturating it, sites of this type must either be quite abundant, or the reactivity of amino acids with them must be small; or each of these factors may play a role.

In any event the present results show that the external barrier of the cell has an exceedingly low permeability to the simple diffusion of these small solute molecules. Perhaps the nature of the barrier material and the molecular spacing within is such 
that a small hydrophilic molecule, whether a metabolite or an entirely foreign substance, would only rarely pass through the plasma membrane without establishing contact with chemical groups of one kind or another within the substance of the membrane.

\section{ACKNOWLEDGEMENTS}

This work was supported in part by the Institute for Child Health and Development (Grant HD or 233), National Institutes of Health, U.S. Public Health Service.

The authors wish to acknowledge the assistance of Miss A. Cullen with the experiments on intestinal uptake.

\section{REFERENCES}

I H. Akedo and H. N. Christensen, J. Biol. Chem., 237 (I962) i i8.

2 H. N. Christensen and M. Liang, J. Biol. Chem., 240 (I965) 3601.

3 H. N. Christensen, T. R. Riggs and N. E. Ray, J. Biol. Chem., I94 (1952) 4I.

4 P. R. Pal and H. N. Christensen, J. Biol. Chem., 236 (I96I) 894.

5 D. L. OXender, J. Biol. Chem., 240 (I965) 2976.

6 D. L. Oxender and H. N. Christensen, $J$. Biol. Chem., 238 (Ig63) 3686.

7 H. N. Christensen, D. L. Oxender, M. Liang and K. VATz, J. Biol. Chem., 240 (I965) 3609.

8 H. N. Christensen, J. Biol. Chem., 239 (1964) 2584.

9 H. N. Christensen, Proc. Natl. Acad. Sci. U.S., 5i (1964) 337

io W. T. Agar, F. J. R. Hird and G. S. Sidhu, Biochim. Biophys. Acta, I 4 (I954) 80.

i I. G. Hempling, Federation Proc., I8 (I959) 67. 